Bol. Soc. Bot. México 31:109-112, 1 fig. (1970)

\title{
HALLAZGO DE UNA ESPECIE NUEVA DE DRABA (CRUCIFERAE) EN EL VALLE DE MEXICO
}

\author{
por Graciela Calderón de Rzedowsisi*
}

En el mes de agosto de 1963, J. Rzedowski colectó en la Sierra de Pachuca, Hgo., una pequeña planta perteneciente a la familia de las Crucíferas, la que desde un principio dio la impresión de pertenecer al género Draba pero era distinta a las conocidas con anterioridad. Una colecta posterior hecha en septiembre de 1969, en la misma localidad, proporcionó nuevo material para su estudio y descripción.

\section{DRABA HIDALGENSIS Calderón sp. n.}

Herba perennis, usque ad $20 \mathrm{~cm}$. alta, scaposa, caespitosa; pubescentia praecipue ex pilis partitis constans; folia maximam partem in densa rosula basilare disposita, sessilia, linearia, basim versus decrescentia, Monocotyledonum folia simulantia, 1.5-4.5 $\mathrm{cm}$. longa, $1-4 . \mathrm{mm}$. lata, margo integer, ciliatus (pilis plerumque simplicibus), costa saepe manifesta, interdum pilosa, apex acutus vel obtusus, foliorum mortuorum bases ut squamae persistentes; folia caulina sessilia, pauca vel absentia, basilaribus breviora; inflorescentiae una vel paucae, a rosulae basi genitae, raro ramosae; sepala glabra vel fere glabra, $1.5-2 \mathrm{~mm}$. longa, petala lutea vel alhida, $1.5-2.5 \mathrm{~mm}$. longa, stamina 6 ; pedicelli fructiferi patentes, siliquae ovatae usque ad lanceolatae, compressae, 4. $8 \mathrm{~mm}$. longae, $2 \cdot 3$ $\mathrm{mm}$. latae, rectae vel interdum curvae, glabrae vel fere glabrae, stylus persistens; semina 2-5 per loculum, ovoidea, cotyledones accumbentes.

Hierba baja, hasta de $20 \mathrm{~cm}$. de alto, frecuentemente de aspecto escaposo, perenne, cespitosa. Pubescencia principalmente de pelos partidos, aunque también se presentan pelos simples.

Raíz pivotante con frecuencia ramificada, de tal manera que salen varios tallos de una raíz común.

Hojas mayormente dispuestas en densa roseta basal, persistiendo las bases de las hojas muertas en forma de escamas; de forma linear (dando la impre-

* Departamento de Botánica, Escuela Nacional de Ciencias Biológicas, Instituto Poli. técnico Nacional, México, D. F. 
sión de hoja de monocotiledónea), de 1.5 a $4.5 \mathrm{~cm}$. de largo por 1 a $4 \mathrm{~mm}$. de ancho, angostándose en la base; ápice agudo u obtuso; borde entero, ciliado (generalmente con pelos simples, a veces partidos); nervio medio con frecuencia evidente, en ocasiones piloso. Hojas caulinas sésiles, espatuladas, más cortas que las anteriores, escasas o nulas.

Inflorescencias corimbosas y cortas en flor, alargadas en fruto, saliendo una o pocas de la base de la roseta, rara vez ramificadas. Pedúnculo de 1 a $10 \mathrm{~cm}$. de largo. Flores, aún en su madurez con tendencia a mantener las cubiertas florales aplicadas; sépalos obovados, glabros o casi glabros, verdes, con los bordes escariosos, amarillentos, de 1.5 a $2 \mathrm{~mm}$. de largo; pétalos unguiculados, venosos, amarillos o blanquizcos (sobre todo en ejemplares secos), emarginados en el ápice, de 1.5 a $2.5 \mathrm{~mm}$. de largo, iguales o sobrepasando un poco el largo de los sépalos. Estambres 6 , tetradínamos o subiguales, filamentos dilatados en la base, donde se encuentran las glándulas nectariferas. Ovario ovoide, estilo presente, estigma pequeño. Frutos sobre pedicelos de 3 a $8 \mathrm{~mm}$. de largo, extendidos a partir del eje de la inflorescencia; silicuas ovadas a lanceoladas, comprimidas, de 4 a $8 \mathrm{~mm}$. de largo por 2 a $3 \mathrm{~mm}$. de ancho, rectas o a veces encorvadas y algo asimétricas; generalmente glabras, pero a veces con muy escasos pelos en los bordes; estilo persistente, de unos $0.5 \mathrm{~mm}$. de largo; semillas colgantes, 2 a 5 en cada lóculo, colocadas en 2 hileras, ovoides, de 1.2 a $1.4 \mathrm{~mm}$. de largo por 0.8 a $1 \mathrm{~mm}$. de ancho; cotiledones acumbentes.

Tipo: MEXICO: HIDALGO: Cerro de las Ventanas, $6 \mathrm{~km}$. al $\mathrm{N}$ de Pachuca; bosque de Abies y claros adyacentes, sobre peñas; Alt. 2900 m. 30-IX-1969; Rzedowski 26804 (ENCB). Ejemplares principalmente en fruto.

Aparte del tipo solo se cuenta con la siguiente colecta que también se ha utilizado para hacer la descripción: MEXICO: HIDALGO: Cerro de las Ventanas, al N de Pachuca; bosque de Abies religiosa; Alt. 2900 m. 4-VIII-1963; Rzedowski 16999 (ENCB). Ejemplares principalmente en flor.

Draba hidalgensis se parece bastante en el aspecto general a Onuris oligosperma (Speg.) Gilg \& Muschler (Draba oligosperma Speg.; D. spegazziniana Dusén) de la región patagónica de los Andes, pero las características de la semilla son distintas (los cotiledones son incumbentes en Onuris), las hojas son más angostas y las flores blancas, de mayor tamaño que en nuestra especie. También se asemeja a $D$. graminea Greene de las Montañas Rocallosas, especialmente en la forma y tamaño del fruto, pero es de porte menor, tiene flores bracteadas y pétalos más largos que los de la planta en cuestión.

Aparentemente D. hidalgensis corresponde a la sección Adenodraba de 0 . E. Schulz (Pflanzenreich IV, 105: 18. 1927) en, la cual están situadas las otras 
especies existentes en el Centro y Sur de México y unas cuantas más de la re gión andina. $D$. jorullensis HBK., de esta sección, es quizá la especie más relacionada con $D$. hidalgensis; sin embargo son patentes algunas diferencias: en la primera, las hojas de la roseta basal son más anchas y generalmente pubescentes, las hojas caulinas se presentan en mayor número y tanto los ovarios como las silicuas suelen ser pubescentes. Por lo que parece, D. jorullensis no ha sido colectada en la Sierra de Pachuca, aunque se conoce de otras localidades del Valle de México.

RESUMEN: Se describe una especie nueva de Draba del Valle de México, a base de ejemplares provenientes de dos colectas hechas en el Cerro de las Ventanas, Sierra de Pachuca. Estado de Hidalgo. D. hidalgensis sp. n. aparentemente está emparentada con D. jorullensis HBK., del Centro y Sur de México, aunque presenta también semejanza superficial con Onuris oligosperma (Speg.) Gilg \& Muschler, de Sudamérica, y con D. graminea Greene, de las Montañas Rocallosas.

SUMMARY: A new species of Draba from the Valley of Mexico is described, on the basis of specimens of two collections made at Cerro de las Ventanas, Sierra de Pachuca, State of Hidalgo. D. hidalgensis sp. n., apparently is related with D. jorullensis HBK., from Central and Southern Mexico, although some superficial resemblance with Onuris oligosperma (Speg.) Gilg \& Muschler from South America and with D. graminea Greene, from the Rocky Mountains, can be observed. 


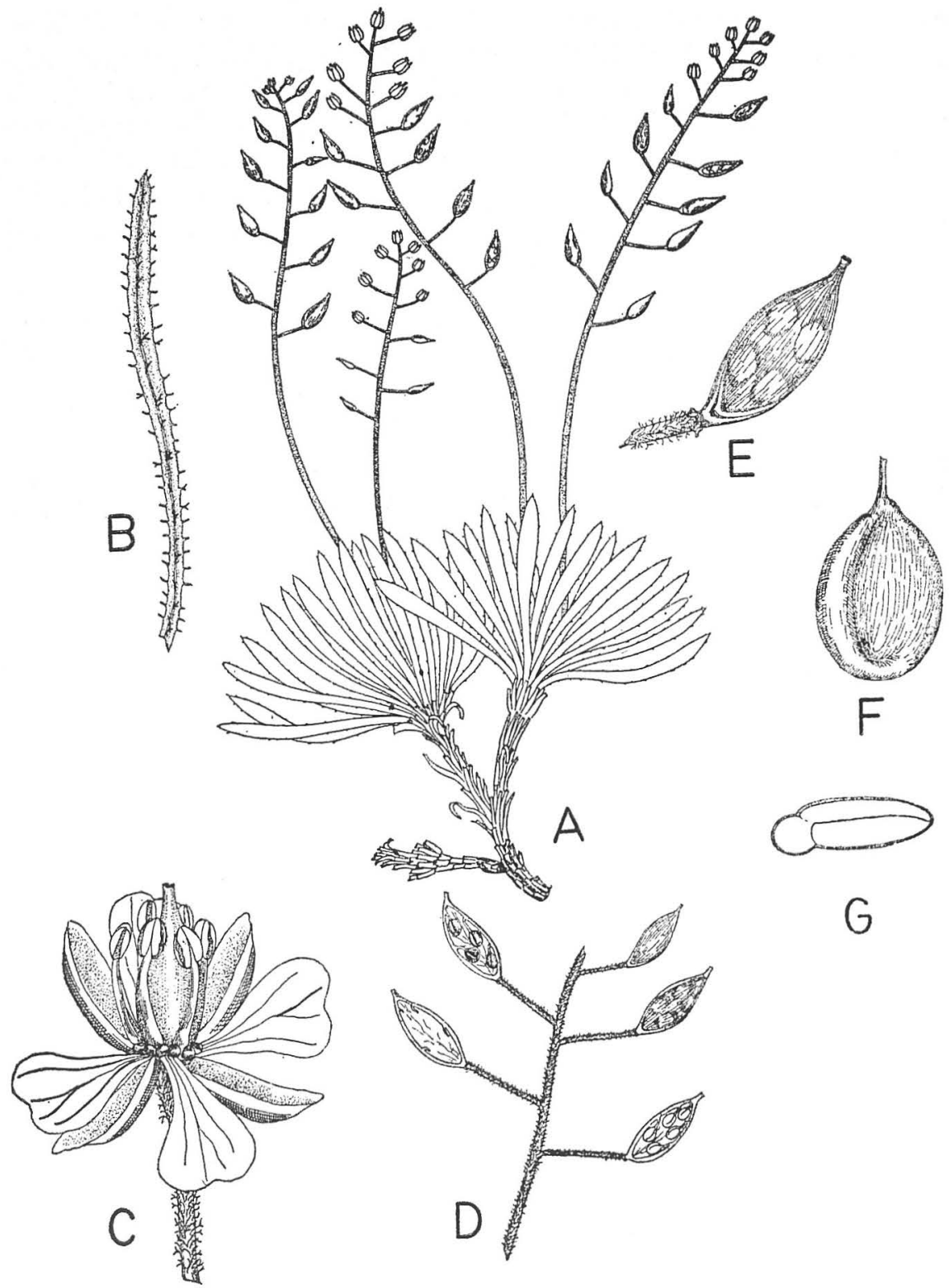

Fig. 1. Draba hidalgensis sp. n. A. Aspecto general de la planta, x 2/3. B. Hoja, x 1. C. Flor artificialmente extendida para mostrar el interior, x 7. D. Porción de la infrutescencia, x 2 . E. Fruto, $\times 3:$ F. Semilla, x 15. G. Corte transversal de la semilla. x 20. 